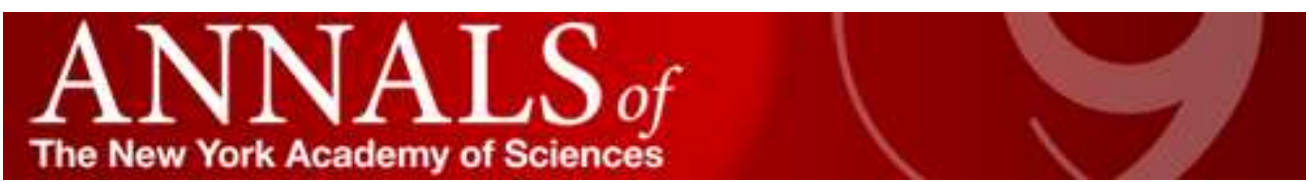

This unedited manuscript has been submitted for publication in the Annals of the NYAS.This paper has not been copyedited.

\title{
Targeting the Age-Related Occurrence, Removal and Accumulation of Molecular Damage by Hormesis
}

\begin{tabular}{|r|l|}
\hline Journal: & Annals of the New York Academy of Sciences \\
\hline Manuscript ID: & Draft \\
\hline Manuscript Type: & Conference papers \\
\hline Date Submitted by the \\
Author: & \\
\hline Complete List of Authors: & Rattan, Suresh; Aarhus University, Department of Molecular Biology \\
\hline Keywords: & anti-aging, hormetin, stress, longevity, heterogeneity \\
\hline
\end{tabular}

\section{scholarONE" \\ Manuscript Central}




\title{
Targeting the Age-Related Occurrence, Removal and Accumulation of Molecular Damage by Hormesis
}

\author{
SURESH I. S. RATTAN \\ Laboratory of Cellular Ageing, Department of Molecular Biology, Aarhus University, \\ Denmark.
}

Address for correspondence: Dr. Suresh Rattan, Department of Molecular Biology, University of Aarhus, Gustav Wieds Vej 10C; DK8000 Aarhus - C, Denmark. Phone: +4589425034; Fax: +4586123178; Email: rattan@mb.au.dk

\begin{abstract}
Strategies for testing and developing effective means of intervention, prevention and modulation of aging incorporate means to minimize the occurrence and accumulation of molecular damage, to reduce molecular heterogeneity, and to evaluate the relevance of the type and extent of damage with respect to its role in aging and agerelated diseases. One such approach is that of mild stress-induced hormesis, which stimulates maintenance and repair systems, and strengthens the homeodynamic space of cells and organisms. Hormesis through mild heat shock, natural and synthetic hormetins, and other stressors brings about several anti-aging effects in human fibroblasts, keratinocytes and telomerase-immortalized bone marrow stem cells. Depending on the cell type, these anti-aging hormetic effects include extension of replicative lifespan, enhanced proteasomal activties, increased chaperone levels, and improved wound healing, angiogenesis and differentiation. The main molecular pathways for achieving such hormetic effects are by targeting the processes for the repair and removal of molecular damage, which can slow down aging.
\end{abstract}

KEYWORDS: anti-aging; hormesis; hormetin; stress; molecular heterogeneity 


\section{INTRODUCTION}

Aging at the molecular level is characterized by the progressive accumulation of molecular damage in nucleic acids, proteins, lipids and carbohydrates. ${ }^{1,2}$ Although the action of the damaging agents is mainly stochastic, the result, whether a specific macromolecule will become damaged and whether a damage can persist, depends on the structure, localization and interactions of the macromolecule with other macromolecules, and on the activity and efficiency of a complex series of maintenance and repair systems (MARS). The resulting increase in molecular heterogeneity has major biological consequences in terms of interrupted networks and illegitimate networks. ${ }^{2}$ More specifically, damage in MARS leads to age-related failure of homeodynamics, altered cellular functioning, reduced stress tolerance, emergence of diseases and ultimate death.

Strategies for testing and developing effective means of intervention, prevention and modulation of aging incorporate means to minimize the occurrence and accumulation of molecular damage, to reduce molecular heterogeneity, and to evaluate the relevance of the type and extent of damage with respect to its role in aging and age-related diseases. One such approach is that of mild stress-induced hormesis, which stimulates MARS, and strengthens the homeodynamic space of cells and organisms. ${ }^{3}$ Hormesis through mild heat shock, natural and synthetic hormetins, and other stressors brings about several anti-aging effects in human fibroblasts, keratinocytes and telomerase-immortalized bone marrow stem cells. Depending on the cell type, these anti-aging hormetic effects include extension of replicative lifespan, enhanced proteasomal activties, increased chaperone levels, and improved wound healing, angiogenesis and differentiation.

\section{STRESS AND HORMESIS}

A critical component of the homeodynamic (homeostatic) property of living systems is their capacity to respond to stress. In this context, the term "stress" is defined as a signal generated by any physical, chemical or biological factor (stressor), which in a living system initiates a series of biological events that enable it to counteract, adapt and survive. Table 1 gives a list of major molecular pathways of stress response in mammalian cells. These include heat shock response (HSR), unfolded protein response (UPR), DNA repair response, antioxidant response, and autophagy, which are integral to the organismic property of homeodynamics. 
Based on the involvement of one or more molecular SR, higher order (cellular, organ level and body level) SR are manifested, which include apoptosis, inflammation, and hyperadrenocorticism.

Not all pathways of the SR respond to every stressor, and although there may be some overlap, generally SR pathways are quite specific. The specificity of the response is mostly determined by the nature of the damage induced by the stressor and the variety of downstream effectors involved. For example, cytoplasmic induction of protein denaturation by heat, heavy metals and antibiotics will initiate HSR by inducing the synthesis of heat shock proteins (HSP) followed by the activation of proteasome-mediated protein degradation. ${ }^{6,11}$ But, unfolded proteins in the endoplasmic reticulum (ER) will induce unfolded protein response (UPR), and will initiate the induction of synthesis of a totally different set of proteins and their downstream effectors. ${ }^{7,12}$

The consequences of SR can be both harmful and beneficial depending both on the intensity, duration and frequency of the stress, and on the price paid in terms of energy utilisation and other metabolic disturbances. But the most important aspect of SR is that it is not monotonic with respect to the dose of the stressor, rather it is almost always characterized by a nonlinear biphasic relationship. Several meta-analyses performed on a large number of papers published in the fields of toxicology, pharmacology, medicine, and radiation biology have led to the conclusion that the most fundamental shape of the dose response is neither threshold nor linear, but is U- or inverted U-shaped, depending on the endpoint being measured. ${ }^{13,14}$ This phenomenon of biphasic dose response was termed as hormesis. ${ }^{15}$

Since several terms such as, autoprotection, heteroprotection, adaptive response, preconditioning, hormesis, xenohormesis and others, have been used to describe the biological responses to various stressors, recommendations have been made for the use of a common terminology which is consistent with the quantitative features of the dose-response and underlying molecular foundations (for historical development of the term, see. ${ }^{16}$ It has been proposed that a common terminology should include the operational term hormesis, which would be preceded by the type of inducing agent and whether or not conditioning was present. ${ }^{13}$ Three main categories of such terms are:

physiological conditioning hormesis, in which an exposure to a stressful condition, such as hypoxia, ischemia, radiation or a toxic chemical, conditions the system to tolerate much higher doses of the same condition 
subsequently

physiological/chemical/radiation hormesis: when hormesis occurs without prior conditioning; and

post-exposure conditioning hormesis: The post-conditioning hormesis in which exposure to high doses of a stressor, such as radiation for cancer therapy, is followed by repeated low dose radiation exposure.

The key conceptual features of hormesis are the disruption of homeodynamics, the modest overcompensation, the reestablishment of homeodynamics and the adaptive nature of the process. An example of stress-induced hormesis is the well documented beneficial effects of moderate exercise as a hormetic agent, which initially increases the production of free radicals, acids and aldehydes. ${ }^{17}$ Another frequent observation in studies of hormesis is that a single hormetic agent, such as heat shock or physical activity, can improve the overall homeodynamics of cells and enhance other activities such as tolerance to other stresses, by initiating a cascade of processes resulting in a biological amplification and eventual beneficial effects. ${ }^{18}$ Hormesis in aging research and anti-aging interventions is represented by mild stress-induced stimulation of protective mechanisms in cells and organisms resulting in biologically beneficial effects. ${ }^{3,18}$

\section{HORMETIC MODULATION OF AGING HUMAN CELLS}

In a series of papers published since 1998, our labs have reported the hormetic effects of mild heat shock (HS; $41^{\circ} \mathrm{C}, 1 \mathrm{hr}$, two times a week) on cultured human skin fibroblasts, keratinocytes and bone marrow stem cells. Table 2 summarises the main results obtained so far. Briefly, these effects include: (i) a reduction in age-related changes in cell morphology, ${ }^{19,20}$ (ii) an increase in cellular replicative lifespan, ${ }^{20}$ (iii) a reduction in the accumulation of damaged proteins, ${ }^{21-23}$ (iv) an increase in intracellular antioxidative abilities, and (v) an increase in resistance to ethanol, hydrogen peroxide and UV-A irradiation. ${ }^{24}$ The main mechanisms involved in bringing about the above beneficial effects of mild HS in fibroblasts require increased levels of various heat shock proteins (HSP),[24] increased proteasomal activities, ${ }^{25}$ and efficient stress kinase activation. ${ }^{20}$ Similar cellular and biochemical hormetic anti-aging effects of repeated exposure to mild HS were observed in normal human epidermal keratinocytes. These effects included maintenance of a relatively 


\section{HORMETINS AND FUTURE PERSPECTIVES}

Several lines of evidence support the view that hormesis can be applied successfully to aging research and intervention. Hormetic stressors have been also termed as hormetins, ${ }^{18}$ and may be categorized as physical, nutritional and mental hormetins, depending on the nature of the hormetic stress. At the mechanistic level, the induction of any set of SR pathways as mediators of hormetic effects is only a partial explanation and cannot account for the wide ranging and long lasting biological effects. Therefore, it is important to determine how various components of the homeodynamic machinery respond and interact during stressinduced hormesis, and how relatively small individual hormetic effects lead to a significant biological amplification that results in an overall improvement of the living system.

The main promise and potential of hormesis as a modulator of aging lies in its mode of action. Since hormetic effects occur by involving a series of molecular and physiological processes, the final target of hormesis is the overall homeodynamic machinery of the living systems. The process of aging is primarily characterized by a progressive shrinking of homeodynamic space in terms of increased molecular heterogeneity, which leads to increased 
vulnerability, onset of diseases and eventual death. ${ }^{2}$ Hormesis appears to be a useful practical approach to target the occurrence and accumulation of molecular damage by strengthening the homeodynamic space and by slowing down its rate of shrinkage during aging.

\section{ACKNOWLEDGEMENTS}

A research grant from Eva and Henry Fraenkel Memorial Fund is gratefully acknowledged.

\section{REFERENCES}

1. Rattan, S.I.S. 2006. Theories of biological aging: genes, proteins and free radicals. Free Rad. Res. 40: 1230-1238.

2. Rattan, S.I.S. 2008. Increased molecular damage and heterogeneity as the basis of aging. Biol. Chem. 389: 267-272.

3. Le Bourg, E. \& S.I.S. Rattan (eds). 2008. Mild stress and healthy aging: applying hormesis in aging research and interventions. Springer. Dordrecht, The Netherlands.

4. Hakem, R. 2008. DNA-damage repair; the good, the bad, and the ugly. Embo J. 27: 589-605.

5. Ishii, T., K. Itoh \& M. Yamamoto. 2002. Roles of Nrf2 in activation of antioxidant enzyme genes via antioxidant responsive elements. Methods Enzymol. 348: 182-190.

6. Liberek, K., A. Lewandowska \& S. Zietkiewicz. 2008. Chaperones in control of protein disaggregation. EMBO J. 27: 328-335.

7. Yoshida, H. 2007. ER stress and diseases. FEBS J. 274: 630-658.

8. Yen, W.L. \& D.J. Klionsky. 2008. How to live long and prosper: autophagy, mitochondria, and aging. Physiol. 23: 248-262.

9. Medzhitov, R. 2008. Origin and physiological roles of inflammation. Nature. 454: 428-435.

10. Longo, V.D. 2009. Linking sirtuins, IGF-I signaling, and starvation. Exp Gerontol. 44: 70-74.

11. Verbeke, P., et al. 2001. Heat shock response and ageing: mechanisms and applications. Cell Biol. Int. 25: 845-857.

12. Banhegyi, G., et al. 2007. Endoplasmic reticulum stress. Ann N Y Acad Sci. 1113: 5871. 
13. Calabrese, E.J., et al. 2007. Biological stress response terminology: integrating the concepts of adaptive response and preconditioning stress within a hormetic doseresponse framework. Toxicol. Appl. Pharmacol. 222: 122-128.

14. Calabrese, E.J. 2008. Hormesis and medicine. Br J Clin Pharmacol. 66: 594-617.

15. Southam, C.M. \& J. Ehrlich. 1943. Effects of extracts of western red-cedar heartwood on certain wood-decaying fungi in culture. Phytopathology. 33: 517-524.

16. Calabrese, E.J. 2002. Hormesis: changing view of the dose-response, a personal account of the history and current status. Mutat. Res. 511: 181-189.

17. Radak, Z., et al. 2008. Exercise, oxidative stress and hormesis. Ageing Res Rev. 7: 3442.

18. Rattan, S.I.S. 2008. Hormesis in aging. Ageing Res. Rev. 7: 63-78.

19. Rattan, S.I.S. 1998. Repeated mild heat shock delays ageing in cultured human skin fibroblasts. Biochem. Mol. Biol. Int. 45: 753-759.

20. Nielsen, E.R., Y. Eskildsen-Helmond \& S.I.S. Rattan. 2006. MAP-kinases and heat shock-induced hormesis in human fibroblasts during serial passaging in vitro. Ann. NY Acad. Sci. 1067: 343-348.

21. Verbeke, P., B.F.C. Clark \& S.I.S. Rattan. 2000. Modulating cellular aging in vitro: hormetic effects of repeated mild heat stress on protein oxidation and glycation. Exp. Gerontol. 35: 787-794.

22. Verbeke, P., B.F.C. Clark \& S.I.S. Rattan. 2001. Reduced levels of oxidized and glycoxidized proteins in human fibroblasts exposed to repeated mild heat shock during serial passaging in vitro. Free Rad. Biol. Med. 31: 1593-1602.

23. Verbeke, P., et al. 2002. Hormetic action of mild heat stress decreases the inducibility of protein oxidation and glycoxidation in human fibroblasts. Biogerontology. 3: 105108.

24. Fonager, J., et al. 2002. Mild stress-induced stimulation of heat shock protein synthesis and improved functional ability of human fibroblasts undergoing aging in vitro. Exp. Gerontol. 37: 1223-1238.

25. Beedholm, R., B.F.C. Clark \& S.I.S. Rattan. 2004. Mild heat stress stimulates proteasome and its $11 \mathrm{~S}$ activator in human fibroblasts undergoing aging in vitro. Cell Stress \& Chaperones. 9: 49-57. 
26. Rattan, S.I.S. \& R.E. Ali. 2007. Hormetic prevention of molecular damage during cellular aging of human skin fibroblasts and keratinocytes. Ann. N.Y. Acad. Sci. 1100: 424-430.

27. Berge, U., J. Behrens \& S.I.S. Rattan. 2007. Sugar-induced premature aging and altered differentiation in human epidermal keratinocytes. Ann. N.Y. Acad. Sci. 1100: 524-529.

28. Nørgaard, R., M. Kassem \& S.I.S. Rattan. 2006. Heat shock-induced enhancement of osteoblastic differentiation of hTERT-immortlized mesenchymal stem cells. Ann. NY Acad. Sci. 1067: 443-447.

29. Rattan, S.I.S., et al. 2007. Stress-mediated hormetic modulation of aging, wound healing and angiogenesis in human cells. Ann N Y Acad Sci. 1119: 112-121.

30. Park, H.G., et al. 2005. Cellular responses to mild heat stress. Cell. Mol. Life Sci. 62: $10-23$.

31. Rattan, S.I.S., et al. 2009. Heat stress and hormetin-induced hormesis in human cells: effects on aging, wound healing, angiogenesis and differentiation. Dose-response. 7: 93-103. 
1

3

TABLE 1: Major molecular level stress responses in human cells.

\begin{tabular}{|c|c|c|c|}
\hline Response & Stressors & Effectors & References \\
\hline $\begin{array}{l}\text { DNA-repair } \\
\text { response }\end{array}$ & $\begin{array}{l}\text { Radiation, } \\
\text { oxidants, free } \\
\text { radicals }\end{array}$ & $\begin{array}{l}\text { DNA-repair } \\
\text { enzymes }\end{array}$ & {$[4]$} \\
\hline $\begin{array}{l}\text { Antioxidant } \\
\text { response }\end{array}$ & $\begin{array}{l}\text { Free radicals, } \\
\text { reactive oxygen } \\
\text { species, pro- } \\
\text { oxidants }\end{array}$ & $\begin{array}{l}\text { Nrf- } 2 \text {, heme- } \\
\text { oxygenase, } \\
\text { FOXO }\end{array}$ & {$[5]$} \\
\hline $\begin{array}{l}\text { Heat shock } \\
\text { response } \\
\text { (HSR) }\end{array}$ & $\begin{array}{l}\text { Heat, heavy } \\
\text { metals, antibiotics, } \\
\text { protein } \\
\text { denaturation }\end{array}$ & $\begin{array}{l}\text { Heat shock } \\
\text { proteins, } \\
\text { proteasome and } \\
\text { other proteases }\end{array}$ & {$[6]$} \\
\hline $\begin{array}{l}\text { Unfolded } \\
\text { protein } \\
\text { response } \\
\text { (UPR) }\end{array}$ & $\begin{array}{l}\text { Unfolded and } \\
\text { misfolded proteins } \\
\text { in endoplasmic } \\
\text { reticulum }\end{array}$ & $\begin{array}{l}\text { Chaperones, co- } \\
\text { chaperones }\end{array}$ & [7] \\
\hline $\begin{array}{l}\text { Autophagic } \\
\text { response }\end{array}$ & $\begin{array}{l}\text { Food starvation, } \\
\text { hypoxia, damaged } \\
\text { organelles }\end{array}$ & Lysosomes & [8] \\
\hline $\begin{array}{l}\mathrm{NF}-\kappa \beta \\
\text { inflammatory } \\
\text { response }\end{array}$ & $\begin{array}{l}\text { Pathogens, } \\
\text { allergens, damaged } \\
\text { macromolecules }\end{array}$ & $\begin{array}{l}\text { cytokines, nitric } \\
\text { oxide synthase }\end{array}$ & [9] \\
\hline $\begin{array}{l}\text { Sirtuin } \\
\text { response }\end{array}$ & Energy depletion & Sirtuins & {$[10]$} \\
\hline
\end{tabular}


TABLE 2: A summary of results on the anti-aging hormetic effects on human cells in culture.

Anti-aging effects on fibroblasts and keratinocytes

- Extension of replicative lifespan. ${ }^{13}$

- Maintenance of youthful morphology. ${ }^{12,13}$

- Reduced extent of accumulation of damaged proteins. ${ }^{14-16}$

- Increased ability of intracellular antioxidative defenses. ${ }^{17}$

- Increased resistance to ethanol, hydrogen-peroxide and UV-A irradiation. ${ }^{17}$

- Increased levels of heat shock proteins. ${ }^{17}$

- Increased activities of the proteasome. ${ }^{18}$

- Maintenance of stress kinase response. ${ }^{13}$

- Increased content and activity of the sodium pump. ${ }^{19}$

Other functional improvements

- Enhanced differentiation of epidermal keratinocytes. ${ }^{20}$

- Enhanced differentiation of bone marrow stem cells. ${ }^{21}$

- Enhanced wound healing in vitro. ${ }^{22,25}$

- Enahanced angiogenesis in vitro by endothelial cells. ${ }^{22,25}$ 